\title{
The Role of Partograph in the Outcome of Spontaneous Labor
}

\author{
Sanyal U, Goswami S, Mukhopadhyay P \\ Department of Obstetrics and Gynaecology, Medical College, Kolkata, India.
}

\begin{abstract}
Aims: The objective of the paper is to study the role of partogram in the outcome of spontaneous labour in primigravidae at term with singleton pregnancy and vertex as the presenting part.

Methods: This prospective observational study was carried out in the labour room of the department of Gynaecology and Obstetrics of Medical College \& Hospital, Kolkata, over a period of one year i.e. from June 2011 to May 2012 after obtaining approval from the institutional ethical committee. Analysis of the progress of labour was done in five hundred women with the help of modified WHO partograph. The study population was divided into three groups. Group I had a total observed duration of active stage six hours or less and their cervicograph remained on or to the left of the alert line. Group II had total observed duration of active phase between more than six hours and less than ten hours and their cervicograph remained between the alert and action line. Group III, who had the duration of observed active phase more than 10 hours, had their cervicograph crossing the action line. The different types of abnormal labor were studied. The maternal and fetal outcomes were assessed.

Results: $80.8 \%$ of the women belonged to group I, $15.2 \%$ to group II and $4 \%$ to group III. Surgical interference increased as the labour curve moved to the right of the alert line. Use of partogram helped in overall reduction in the duration of labour. Timely intervention reduced the incidence of prolonged labour and its sequelae. $19.2 \%$ of the women showed abnormal labour. Severe complications were successfully averted. There were no cases of maternal death, puerperal sepsis, ruptured uterus or fresh still births. Overall neonatal mortality rate was also reduced.
\end{abstract}

Conclusions: The use of modified WHO partograph significantly improves the outcome of labour in both maternal \& neonatal perspective. The WHO partograph should be used in all maternity units with incorporated management guidelines.

Keywords: labor, partograph, prolonged labor.

\section{INTRODUCTION}

Labour has been termed as the most dangerous journey a woman ever undertakes. Though it is a physiological phenomenon leading to childbirth, complications can occur anytime during its course. ${ }^{1}$ Many women have the rewarding experience of a safe birth of a healthy baby, while a small proportion continue to face the complications of abnormal labor or dystocia and its sequelae.

Maternal mortality ratio in India at present is 212 per 100,000 live births. ${ }^{2}$ Important causes of maternal morbidity and mortality are sepsis, postpartum hemorrhage, urinary fistula and uterine rupture. All these are precedent to perinatal deaths, asphyxia and neonatal sepsis.

\section{CORRESPONDENCE}

Dr Urmi Sanyal

Department of Obstetrics and Gynaecology, Medical College

Kolkata, West Bengal, India

Email: urmisanyal@gmail.com

Phone: +91-9830292205
Partograph acts as a simple and accurate instrument for early recognition of abnormalities during labour. This prevents prolonged and obstructed labour and alters maternal and fetal outcomes favourably. Freidman introduced the concept of partograph ${ }^{3,4}$ in 1954 by graphically depicting the dilatation of cervix during labour. In 1972, Philpott and Castle ${ }^{5,6}$ modified the concept by the addition of 'action line' and 'alert line' in the graph. At present, the partograph is endorsed by WHO.

\section{METHODS}

This prospective observational study was carried out in the labour room of the department of Gynaecology and Obstetrics of Medical College and Hospital, Kolkata over a period of one year i.e. from June 2011 to May 2012. Five hundred cases admitted to labour room were selected according to the inclusion criterias and monitored by using modified WHO partograph. The study was done after receiving the approval of the institutional ethical committee. Informed consent was taken from each subject. 
Primigravida or nulliparous women at 37 to $42 \mathrm{wks}$ of singleton pregnancy and vertex as the presenting part were included in the study. Non vertex presenting part, known major fetal structural anomalies, previous uterine surgery, antepartum hemorrhage, premature rupture of membranes, intrauterine growth retardation, intra uterine fetal death and medical disorders like anemia, hypertension, diabetes, immunocompromised state were excluded from the study. Patients were monitored in the labour room and the progress of labour and other vital information were recorded in the WHO modified partograph. Individual partograph was studied to know the various aspects related to the course of labour. The role of partograph in influencing decision making in abnormal progress of labour was assessed. The mode of delivery was ascertained. Necessary data was collected in a structured format. The data was transferred to the master chart. Standard statistical tests (chi square, unpaired t test, etc) were used where ever applicable.

According to the observed pattern of labour progression and its duration, the women were divided into three groups. Group I had a total observed duration of active stage six hours or less and their cervicograph remained on or to the left of the alert line. Group II had total observed duration of active phase more than six hours and less than 10 hours and their cervicograph remained between alert and action line. Group III, with their observed active phase duration more than 10 hours, had their cervicograph crossing the action line. The various abnormal patterns of labour observed were categorized into dilatation disorders and descent disorders. These are protracted dilatation (less than $1.2 \mathrm{~cm}$ per hour), protracted descent (less than $1 \mathrm{~cm}$ per hour), arrest of dilatation (no dilatation for more than 2 hours), arrest of descent(no descent of the presenting part for more than 1 hour) and failure of descent(complete cessation of descent of the presenting part).

The need for augmentation of labour by artificial rupture of membrane and oxytocin infusion was assessed in cases of abnormal labor. The augmentation of labor was done with oxytocin infusion, whenever uterine inertia was diagnosed as the cause for the delay in the progress of labour. Judicious use of analgesics was done when and where necessary.
Cases showing abnormal course of labour were reevaluated by senior obstetrician and decision of any operative intervention, if required, was taken accordingly. Broad spectrum antibiotics were given to those cases, which required operative intervention.

Babies were properly resuscitated following delivery and assessed by pediatrician. Neonatal assessment was done using Apgar score at 1 minute and 5 minutes.

\section{RESULTS}

Out of the 500 women, maximum number of women (56\%) belonged to the 21-25 yrs age group. The period of gestation of the majority of women (84\%) at the time of admission was between 38.1 to 40 weeks.

It is evident from Table 1 that majority of the women delivered vaginally (79.2\%). On the other hand, $5.2 \%$ required instrumental delivery. Lower segment cesarean delivery (LSCD) was performed in 15.6 $\%$ women, commonest indication being abnormal pattern of labour.

$404(80.8 \%)$ women delivered before alert line (group I) and $76(15.2 \%)$ women between alert and action line (group II) and 20 (4\%) women beyond action line (group III).

Majority women (94 \%) in Group I underwent spontaneous vaginal delivery while $2 \%$ required instrumental delivery and $4 \%$ had lower segment cesarean delivery. On the other hand, cesarean delivery rate was more in group II i.e. $57.9 \%$ and highest in group III i.e. 90\%. Spontaneous vaginal delivery in group II and group III were $18.4 \%$ and $10 \%$ respectively.

Table 1. Mode of delivery in relation to observed duration of the active phase $(n=500)$.

\begin{tabular}{|c|c|c|c|c|c|c|}
\hline $\begin{array}{l}\text { Mode of } \\
\text { delivery }\end{array}$ & $\begin{array}{l}\text { Group } \\
\mathrm{I}(\%)\end{array}$ & $\begin{array}{l}\text { Group } \\
\mathrm{II}(\%)\end{array}$ & $\begin{array}{l}\text { Group } \\
\text { III (\%) }\end{array}$ & $\begin{array}{l}\text { Total } \\
(\%)\end{array}$ & $P$ value & $\begin{array}{l}\text { Signi } \\
\text {-ficance }\end{array}$ \\
\hline Spontaneous & $\begin{array}{l}380 \\
(94)\end{array}$ & $\begin{array}{l}14 \\
(18.4)\end{array}$ & $2(10)$ & $\begin{array}{l}396 \\
(79.2)\end{array}$ & \multirow{4}{*}{$<0.001$} & \multirow{4}{*}{$\begin{array}{l}\text { Signi } \\
\text {-ficant }\end{array}$} \\
\hline Instrumental & $8(2)$ & $\begin{array}{l}18 \\
(23.7)\end{array}$ & $0(0)$ & $\begin{array}{l}26 \\
(5.2)\end{array}$ & & \\
\hline LSCD* & $16(4)$ & $\begin{array}{l}44 \\
(57.9)\end{array}$ & $\begin{array}{l}18 \\
(90)\end{array}$ & $\begin{array}{l}78 \\
(15.6)\end{array}$ & & \\
\hline Total & $\begin{array}{l}404 \\
(100)\end{array}$ & $\begin{array}{l}76 \\
(100)\end{array}$ & $\begin{array}{l}20 \\
(100)\end{array}$ & $\begin{array}{l}500 \\
(100)\end{array}$ & & \\
\hline
\end{tabular}

*LSCD: Lower segment Cesarean Delivery 
Table 2. Duration of Labour with respect to normal and abnormal pattern of labour.

\begin{tabular}{lllll}
\hline $\begin{array}{l}\text { Observed } \\
\text { duration }\end{array}$ & $\begin{array}{l}\text { Normal } \\
(\text { Mean } \pm \text { S.D*) }\end{array}$ & $\begin{array}{l}\text { Abnormal } \\
(\text { Mean } \pm \text { S.D*) }\end{array}$ & P value & Significance \\
\hline $\begin{array}{l}\text { Active Phase } \\
\text { of }\end{array}$ & $4.93 \pm 0.89$ & $8.70 \pm 1.62$ & $<0.001$ & Significant \\
$\begin{array}{l}1^{\text {st }} \text { stage } \\
\text { (hours) }\end{array}$ & $36.67 \pm 11.72$ & $76.19 \pm 32.21$ & $<0.001$ & Significant \\
$\begin{array}{l}\text { 2nd Stage } \\
\text { (minutes) }\end{array}$ & & & & \\
\hline
\end{tabular}

*S.D: Standard Deviation

Table 2 shows that the average duration of observed active phase of labour was 4.93 hours in primigravidae showing normal progress of labour and the average rate of cervical dilatation during active phase was $1.2 \mathrm{~cm} / \mathrm{hr} .19 .2 \%$ of women in the study population had abnormal course of labour. Average duration of observed active phase in these cases was 8.7 hours and the rate of cervical dilatation was 0.7 $\mathrm{cm} / \mathrm{hr}$. Average duration of second stage in normal and abnormal labour was 36.67 minutes and 76.19 minutes respectively.

Table 3. Distribution of the mode of Delivery in relation to different Patterns of Abnormal Labour ( $n=96)$.

\begin{tabular}{lllll}
\hline $\begin{array}{l}\text { Pattern } \\
\text { of abnormal } \\
\text { labor }\end{array}$ & $\begin{array}{l}\text { Cases } \\
(\%)\end{array}$ & $\begin{array}{l}\text { Spont } \\
\text { aneous } \\
(\%)\end{array}$ & $\begin{array}{l}\text { Instru } \\
\text { mental } \\
(\%)\end{array}$ & $\begin{array}{l}\text { LSCD* } \\
(\%)\end{array}$ \\
\hline $\begin{array}{l}\text { Arrest of } \\
\text { descent }\end{array}$ & $11(11.5)$ & 0 & $8(8.3)$ & $3(3.1)$ \\
$\begin{array}{l}\text { Arrest of } \\
\text { dilatation }\end{array}$ & $27(28.1)$ & 0 & 0 & $27(28.1)$ \\
$\begin{array}{l}\text { Failure of } \\
\text { descent }\end{array}$ & $4(4.2)$ & 0 & 0 & $4(4.2)$ \\
$\begin{array}{l}\text { Protracted } \\
\text { descent }\end{array}$ & $19(19.8)$ & $4(4.2)$ & $10(10.4)$ & $5(5.2)$ \\
$\begin{array}{l}\text { Protracted } \\
\text { dilatation }\end{array}$ & $35(36.5)$ & $12(12.5)$ & 0 & $23(24)$ \\
$\begin{array}{l}\text { Total } \\
\text { *LSCD: Lower segment Cesarean Delivery }\end{array}$ & $18(18.7)$ & $66(68.7)$ \\
\hline
\end{tabular}

According to Table 3, the commonest pattern of abnormal labour was protracted dilatation (36.5\%). Others were arrest of dilatation $(28.1 \%)$, protracted descent (19.8\%), arrest of descent (11.5\%) and failure of descent (4.2\%). Among the 96 women exhibiting abnormal pattern of labour, $64.6 \%$ required cesarean deliveries, $18.7 \%$ required instrumental delivery while only remaining $16.7 \%$ delivered by spontaneous vaginal delivery. All the cases of arrest of dilatation, arrest of descent and failure of descent required operative intervention. Spontaneous vaginal delivery was possible in 4 out of 19 cases of protracted descent and 12 out of 35 cases of protracted dilatation

After proper evaluation gross cephalopelvic disproportion was suspected in five out of 96 women (who crossed alert line) and operative delivery decided without trial of labour. In the rest, the status of membrane was checked per vaginally. Seven women were found to have spontaneous rupture of membrane and in the remaining $84(87.5 \%)$ women, artificial rupture of membrane done. These 91 women were then augmented with oxytocin infusion. Out of the women in whom artificial rupture of membrane was done and oxytocin was started, majority $61.92 \%$ had lower segment cesarean section, the main indication being fetal distress.

Table 4. Maternal Morbidity in relation to type of labor.

\begin{tabular}{llll}
\hline \multicolumn{4}{c}{ Pattern of labor } \\
$\begin{array}{l}\text { Type of } \\
\text { morbidity }\end{array}$ & $\begin{array}{l}\text { Normal } \\
(\mathrm{n}=404)(\%)\end{array}$ & $\begin{array}{l}\text { Abnormal } \\
(\mathrm{n}=96)(\%)\end{array}$ & Total \\
\hline $\mathrm{PPH}^{*}$ & $6(1.5)$ & $8(8.3)$ & $14(2.8)$ \\
Fever & $4(1)$ & $6(6.2)$ & $10(2)$ \\
Puerperal Sepsis & $0(0)$ & $0(0)$ & $0(0)$ \\
Need for BT ${ }^{\dagger}$ & $0(0)$ & $4(1)$ & $4(0.8)$ \\
Wound Complication & $8(2)$ & $12(12.5)$ & $20(4)$ \\
Average Hospital Stay & 2.00 & 4.81 & 2.54 \\
\hline * PPH: Postpartum Hemorrhage, ${ }^{\dagger} \mathrm{BT}$ : blood transfusion &
\end{tabular}

Table 4 shows that post partum hemorrhage occurred in $1.5 \%$ in normal labour and no one required blood transfusion. Post partum hemorrhage was significantly greater in abnormal labour i.e. $8(8.3 \%)$ and $4(50 \%)$ out of the 8 cases needed blood transfusion. Fever occurred in 1\% cases of normal labour and $6.2 \%$ cases of abnormal labour. Wound complications were also more in abnormal labour $(12.5 \%)$ than normal labour $(2 \%)$. Average hospital stay was only two days in normal labour but 4.81 days in abnormal labor. There were no cases of puerperal sepsis or maternal death and severe maternal complications were successfully averted. 
Table 5. Neonatal outcome in relation to type of labor.

\begin{tabular}{lccc}
\hline \multicolumn{4}{c}{ Pattern of labor } \\
Neonatal & $\begin{array}{c}\text { Normal } \\
\text { morbidity }\end{array}$ & $\begin{array}{c}\text { Abnormal } \\
(\mathrm{n}=404)(\%)\end{array}$ & Total \\
\hline Apgar score at 1 min $<7$ & $67(16.6)$ & $63(65.6)$ & $130(26)$ \\
Apgar score at 5 min $<7$ & $43(10.6)$ & $43(44.8)$ & $86(17.2)$ \\
NICU* admission & $51(12.6)$ & $43(44.8)$ & $94(18.8)$ \\
Received Antibiotics & $51(12.6)$ & $43(44.8)$ & $94(18.8)$ \\
Neonatal Mortality & $4(0.99)$ & $8(8.3)$ & $12(2.4)$ \\
\hline
\end{tabular}

*NICU : Neonatal Intensive Care Unit

From Table 5 it is evident that $44.8 \%$ of babies required neonatal intensive care unit (NICU) admission in cases of abnormal pattern of labour and $12.6 \%$ in cases of normal pattern. Majority babies recovered completely before discharge from hospital. Neonatal mortality in the study group was $2.4 \%$, eight in cases of abnormal pattern and four in cases of normal pattern of labour. Neonatal mortality was reduced by early detection of dystocia and timely intervention.

\section{DISCUSSION}

In the under-resourced settings, prolonged labor and delay in decision-making are important causes of adverse obstetric outcome. This is especially true in the third world countries, like India, where owing
Current study was carried out in the labour room of a tertiary care hospital where on average 14,000 deliveries take place per year.

The graphic form of partograph introduced by Philpott and Castle (1972) $)^{5,6}$ showed that once the alert line in the partograph is crossed, the attendant is alerted of the possibility of an abnormal situation and crossing of the action line effectively separates the dysfunctional or abnormal labour requiring immediate action. The Table- 6 shows a comparative view of studies by Friedman, Shinde, Javed and the present study.

The observations in all the above studies show that the operative interference is increased as the labour curve moves to the right of the alert line and it is significantly increased as the labour curve crosses the action line.

Some authors had suggested that the use of partograph may facilitate reduction of primary caesarean section rate. However Lavender et al found no evidence of any difference between partograph and no partograph in caesarean section. ${ }^{8}$ Similarly, Windrim et $\mathrm{al}^{9}$

Table 6. Comparison between different studies.

\begin{tabular}{|c|c|c|c|c|c|c|c|c|c|}
\hline & \multicolumn{3}{|c|}{ Group I } & \multicolumn{3}{|c|}{ Group II } & \multicolumn{3}{|c|}{ Group III } \\
\hline & $\mathrm{SpD}^{*}$ & $\operatorname{InsD}^{\dagger}$ & $\mathrm{LSCD}^{\dagger \dagger}$ & $\mathrm{SpD}^{*}$ & $\mathrm{InsD}^{\dagger}$ & $\mathrm{LSCD}^{\dagger \dagger}$ & $\mathrm{SpD}^{*}$ & $\mathrm{InsD}^{\dagger}$ & $\mathrm{LSCD}^{\dagger \dagger}$ \\
\hline Freidman's study ${ }^{34}$ & $92.3 \%$ & $1.5 \%$ & $6.2 \%$ & $61.9 \%$ & $4.7 \%$ & $33.3 \%$ & $21.4 \%$ & $7.1 \%$ & $71.4 \%$ \\
\hline Shinde et $\mathrm{al}^{7}$ & $96.2 \%$ & $12 \%$ & $2.8 \%$ & $58.3 \%$ & $25 \%$ & $16.7 \%$ & $14.3 \%$ & 0 & $85.7 \%$ \\
\hline Javed et al ${ }^{1}$ & $88 \%$ & $5.6 \%$ & $6.4 \%$ & $72.4 \%$ & $13.8 \%$ & $13.8 \%$ & $18 \%$ & $45.6 \%$ & $36.4 \%$ \\
\hline Present study & $94.1 \%$ & $2 \%$ & $4 \%$ & $18.4 \%$ & $23.7 \%$ & $57.9 \%$ & $10 \%$ & 0 & $90 \%$ \\
\hline
\end{tabular}

*SpD: spontaneous delivery; ${ }^{\dagger}$ InsD: instrumental delivery; ${ }^{\dagger}$ LSCD: lower segment caesarean section

to resource constraints it is usually not possible to monitor each woman continuously throughout the duration of labor. In such settings, the partograph serves a simple and inexpensive tool to monitor labor in a cost-effective way. Early detection of abnormal pattern of progress and prevention of prolonged labor can significantly improve the outcome of labor. reports an increase in caesarean section rates with the use of partograph. Although very unevenly distributed, $15 \%$ of births worldwide occur by CS, Latin America and the Caribbean show the highest rate (29.2\%), and Africa shows the lowest (3.5\%). In developed countries, the proportion of caesarean births is $21.1 \%$ whereas in least developed countries only $2 \%$ of deliveries are by cesarean section. ${ }^{17}$ 
The mean duration of both the active phase of first stage and second stage of labour in the study group were more in cases with abnormal than that of normal labour patterns. When we consider the incidence of prolonged labour with the use of partograph, it is significantly reduced in our study with none of the women having labour beyond 12 hours. Javed et $\mathrm{al}^{1}$ reported that introduction of partograph showed significant impact on duration of labour as well as on mode of delivery. Similar findings have been reported by a number of authors. ${ }^{10,11}$ The impact on the duration of labour is significant as it will further bring a reduction in maternal and neonatal morbidity.

It can be also derived from the study that the rate of cervical dilatation was slower in women with abnormal labour pattern. The rate of cervical dilatation was more in women, who reported in active phase of labour than women in latent phase of labour. It was more in women with engaged head than in those with unengaged head .The average rate of cervical dilatation in primigravidae reported by other authors was $1.7 \mathrm{~cm} / \mathrm{hr} .{ }^{4,5,18,19}$ The average rate of cervical dilatation in the active phase was $1.3 \mathrm{~cm} / \mathrm{hr}$. According to Friedman's Graph ${ }^{3,4}$ the rate of cervical dilation is 1.2 to $6.8 \mathrm{~cm}$ per hour.

In our study the reasons for dilatation and descent abnormalities were mainly mainly found to be cephalopelvic disproportion or uterine dysfunction. These abnormalities were detected in time and women were delivered by caesarean section. Incidence of arrest of descent was 5-6\% in a study carried out by Friedman. ${ }^{12,13}$ Secondary arrest, which occurs in $5-10 \%$ of labors in most series of Bottoms and associates. ${ }^{14}$ Present study had majority cases of labour abnormality related to cervical dilatation. Many authors have reported protracted cervical dilatational abnormalities as more common than descent abnormalities. ${ }^{15,16}$ However, some studies have shown more incidence of descent abnormalities and few dilatation abnormalities.

The morbidity was more in abnormal labour than in normal labour. Morbidity was mainly related to postpartum hemorrhage, fever and wound sepsis. Thus, it was more in cases, who had undergone operative interventions. Maternal morbidity was responsible for increase in hospital stay by few days. The average hospital stay was more in women with abnormal than in normal labour. Shinde et al ${ }^{7}$ reports a maternal morbidity of $3.52 \%$ in cases having normal labour pattern whereas, it was $53.33 \%$ in cases with abnormal labour pattern. Khan and Rizvi ${ }^{14}$ found that partograph prevented rupture uterus in planned labour after caesarean delivery. Javed ${ }^{1}$ found that by using partograph, frequency of postpartum hemorrhage, ruptured uterus and puerperal sepsis was reduced.

The incidence of neonatal morbidity was also more in women with abnormal course of labour than with normal course of labour. Babies Women born following normal course of labor had milder form of asphyxia as compared to those born following abnormal course. Babies of women with second stage or descent abnormalities had more likelihood of asphyxia. There were no fresh still births in the present study due to routine use of partograph and by early detection of abnormal pattern of labour and its consequences and proper interference in time. Early neonatal mortality due to neonatal sepsis and meconium aspiration were seen in eight newborns in abnormal pattern group and six newborns in the normal pattern. Neonatal morbidity and mortality were seen mainly in women, who had longer duration of labour, multiple internal examinations and operative vaginal or abdominal deliveries. Javed et $\mathrm{al}^{1}$ reports that before introduction of partograph, 48 (9.6\%) babies needed resuscitation with Apgar score less than 6 . This need for resuscitation dropped to $21(4.2 \%)$ in those delivering with partographic monitoring. Two fresh stillbirths and 7 neonatal deaths occurred in non partograph group and there were two fresh stillbirths in partograph group. Perinatal mortality decreased from $3.6 \%$ to $0.8 \%$ showing significant impact of partograph on neonatal outcome $(p<0.03)$. The present study prevented fresh still births.

\section{CONCLUSIONS}

The very meaning of the word obstetrics or "obs stare' i.e. "I stand by" indicates the role of the obstetrician. But this 'standing by' is not merely without interpretation and monitoring. It is a watchful expectancy with the need to intervene when the circumstances necessitate.

Labor which is so utterly a normal biological process in majority can have major and various deviations from the normal track. An ideal tool for supervision and detection of the abnormality at the earliest 
possible stage is the partograph which is simple and specific yet with a scientific base. The partograph helps in identification of the vagaries of labour at the right time by application of scientific thoughts and thus prevents the consequences from taking an obtuse turn.

Partograph is a practical device in a busy labour room with many patients but limited personnel to screen the abnormal labour. With its use, there is no need to record labour events repeatedly in words. It predicts deviation from normal progress of labour and proper intervention can be done in time. It facilitates handover among medical personnel and responsibility and accountability of the person conducting labour.

\section{DISCLOSURE}

The authors report no conflicts of interest in this work.

No violation of human rights and safety.

Funding: Nil

\section{REFERENCES}

1. Iffat $\mathrm{J}$, Shereen B, Tabassum S. Role of partogram in preventing prolonged labour. JPMA. 2007;57:408.

2. Hogan C, Foreman J, Naghavi M, Ahn Y, Wang M, Makela M, et al. Maternal mortality for 181 countries, 1980-2008: a systematic analysis of progress towards Millennium Development Goal 5. The Lancet. 2010;375(9726):160923.

3. Friedman, Emanuel A. Graphic analysis of labor. AJOG 1954;68:1568-75

4. Wayne R, Friedman, Emanuel A. Labor: clinical evaluation and management. New York, Appleton-Century Crofts. 1978:2

5. Philpott RH, Castle WM. Cervicographs in management of labour in primigravidae I. The alert line for detecting abnormal labour. Journal of Obstet and Gynaecol $\mathrm{Br}$ Commonw. 1972;79:592-8.

6. Philpott RH, Castle WM. Cervicographs in the management of labour in primigravidae II. The action line and treatment of abnormal labour. Journal of Obstet and Gynaecol Br Commonw. 1972;79:599-602.

7. Kunaal KS, Bangal B, Singh K. Study of Course of Labour by modified WHO partogram. International Journal of Biomedical and Advance Research. 2012;3:391-96.

8. Lavender T, Hart A, Smyth RM. Effect of partogram use on outcomes for women in spontaneous labor at term. Cochrane database systemic review. 2013;7: CD005461.

9. Rory W, Seaward PG, Hodnett E, Akoury H, Kingdom J, Salenieks, et al. A Randomized Controlled Trial of a Bedside Partogram in the Active Management of Primiparous Labour. JOGC. 2007; 29(1):27-34.

10. Cohen CR, O'Brien WF, Lewis L, Knupel RA. A prospective randomized study of aggressive management of early labour. AJOG. 1987;157:1174-7.
11. Randhawa I, Gupta KB, Kanwal M. A study of prolonged labour. Journal of Indian Medical Association. 1991; 89:161-3.

12. Friedman EA, Kroll BH. Computer analysis of labour progression. Journal of Obstet and Gynaecol Br Commonw. 1969;76:1075-79.

13. Friedman EA, Kroll BH. Computer analysis of labor progression II: Distribution of data and limits of normal. Journal of Reproductive Medicine. 1971;6:20-25.

14. Khan KS, Rizvi A. The partograph in the management of labor following caesarean section. International Journal of Gynecology and Obstetrics. 1995 Aug; 50(2):151-7.

15. Bottoms SF, Hirsch VJ, Sokol RJ. Medical management of arrest disorders of labor: A current overview. AJOG. 1987; 156:935.

16. Melmed H, Evans M. Predictive value of cervical dilatation rates. I. Primipara labor. Obstetric Gynecology. 1976;47:511.

17. Betran AP. Pediatric perinatal epidemiology. 2007 Mar; 21(2):98-113

18. Hendricks CH, Brenner WE, Kraus G. Normal cervical dilatation patterns in late pregnancy and labour. AJOG. 1970;106:1065-82.

19. Sizer AR, Evans J, Bailey SM, Wiener J. A second-stage partogram. Obstetric Gynecology. 2000 Nov;96(5 Pt 1):678-83. 